\title{
Reflections on Deploying Distributed Consultation Technologies with Community Organisations
}

\author{
Ian G Johnson', John Vines ${ }^{1}$, Nick Taylor ${ }^{2}$, Edward Jenkins', Justin Marshall ${ }^{\mathbf{3}}$ \\ ${ }^{1}$ Open Lab \\ ${ }^{2}$ DJCAD \\ ${ }^{3} \mathrm{AIR}$ \\ Newcastle University \\ University of Dundee \\ Dundee, UK \\ Newcastle upon Tyne, UK \\ \{i.g.johnson1, john.vines, \\ edward.jenkins\}@ncl.ac.uk \\ Falmouth University \\ Falmouth, UK \\ n.x.taylor@dundee.ac.uk \\ justin.marshall@falmouth.ac.uk
}

\begin{abstract}
In recent years there has been an increased focus upon developing platforms for community decision-making, and an awareness of the importance of handing over civic platforms to community organisations to oversee the process of decision-making at a local level. In this paper, we detail fieldwork from working with two community organisations who used our distributed situated devices as part of consultation processes. We focus on some of the mundane and often-untold aspects of this type of work: how questions for consultations were formed, how locations for devices were determined, and the ways in which the data collected fed into decision-making processes. We highlight a number of challenges for HCI and civic technology research going forward, related to the role of the researcher, the messiness of decision making in communities, and the ability of community organisations to influence how citizens participate in democratic processes.
\end{abstract}

\section{Author Keywords}

Situated displays; civic technology; civic engagement; voting; ethnography.

\section{ACM Classification Keywords}

H.5.m. Information interfaces and presentation (e.g., HCI): Miscellaneous

\section{INTRODUCTION}

It is well acknowledged that HCI research has a significant role to play in understanding how digital technology can facilitate and support new forms of civic engagement. Over the last five years, we have seen a wealth of work where technology has been used as a means for collecting community opinion $[28,45]$ to support community activists and community organisations to gather data [47] and facilitate discussion around political decision making [11].

Permission to make digital or hard copies of part or all of this work for personal or classroom use is granted without fee provided that copies are not made or distributed for profit or commercial advantage and that copies bear this notice and the full citation on the first page. Copyrights for thirdparty components of this work must be honored. For all other uses, contact the Owner/Author.

Copyright is held by the owner/author(s).

CHI'16, May 07-12, 2016, San Jose, CA, USA

ACM 978-1-4503-3362-7/16/05.

http://dx.doi.org/10.1145/2858036.2858098

(c) (i)

These emerging landscapes for HCI research typically require extensive working with and within communities $[13,44]$, and often come laden with ideals around supporting new forms of democracy and participation in civic life. Furthermore, it involves placing greater emphasis not on just designing systems to collect public opinion, but to design systems for citizens, civic groups and local government to collect public opinion from others.

In this paper, we build on this prior work by detailing our experiences of collaborating with community organisations who used our 'Viewpoint' situated consultation technologies. We discuss fieldwork from two collaborative projects where our voting devices have been deployed to collect opinion on specific issues at different stages of campaigns and participatory governance exercises. Rather than focusing primarily on an evaluation of Viewpoint 'in use', we highlight the various trade-offs and decisions made before, and the making sense and use of collected data following deployment of the devices. Following $[13,14,15]$ we highlight some of the human work that goes into planning and overseeing the use of consultation technologies for community organisations, and the ways in which the research team guided and influenced this process. Our reflections on this fieldwork highlight specific issues related to: the forming of the right questions to be posed on the devices; the identification of and gaining access to the right locations for promoting engagement and discussion; and the difficulties community organisations face in using and responding to the data and insights collected through novel consultation technologies.

Our contributions to the developing HCI discourse surrounding civics technology are two-fold. First, through rich ethnographic insights we highlight stakeholder (researcher and community partner) influence and responsibilities in deployments of community consultation technologies. Second, based on our two case studies, we highlight challenges and opportunities for HCI researchers working with communities and civic organisations, while problematising the perceived neutrality of community consultation technologies in contexts where only a privileged few set the questions, situate the devices and have access to the data. 


\section{HCI AND THE CIVIC TURN}

The field of HCI has for many years dealt with issues to do with civic action, engagement and participation. A huge amount of work within the CSCW and CHI communities has examined how social media services are appropriated for civic discourse [11], information sharing [42], activism [30], protest [46], and action [25,39]. Alongside studying the role of technology in relation to issues of civic importance, there has been increased attention paid to conducting in-the-wild studies of systems in community and civic contexts. Going back over 15 years, projects such as Civic Nexus [34] and CiVicinity [5] have highlighted the benefits of closely collaborating with communities to create Participatory design and systems that connect local actors and transform practices in voluntary and community sector organisations. More recently, a number of studies have explored how technology can support new forms of community engagement and participation in local decisionmaking. Much of this work has focused upon the evaluation of situated displays in public places to engage citizens in voting, consultation, and other forms of sharing and contributing to such processes (e.g. [8,20,22,24,43]). For example, ongoing work in Oulu, Finland, has articulated the value of interactive public displays in engaging members of the public in commentating and giving feedback on planning proposals [23]. Taking a different approach, in the Bespoke project, Taylor et al. [45] deployed their Viewpoint technology as a simple means for local government representatives to set questions for community members to respond to. The ambition here was to promote wider participation, and a sense of increased efficacy, for community residents. Koeman et al. [28] took an approach to distributing voting boxes at multiple locations around communities. Again, like Taylor et al. [45], they harness lightweight forms of engagement to promote participation in opinion sharing-however, they took a further step in visualising the results on a location-by-location basis, as well as in a 'neutral' ground, which promoted wider discussion around the contrasts and divisions within the community itself.

For a long time, the participatory design and community informatics literature-along with wider participatory research scholarship-has discussed, articulated and debated the challenges involved in working with community organisations and facilitating new practices and processes [2,6,34]. Issues such as these are becoming of increasing importance to the HCI scholarship on civic and community technology. This is especially so, given that HCI researchers are no longer just deploying technologies for opinion gathering and consultation-rather, in many respects, they are aiming to support others in developing such practices. This is particularly recognisable in Vlachokyriakos et al's [47] work on PosterVote, where the ambition was to build platforms to be appropriated and deployed by activists, rather than deploying it and evaluating it on their behalf. Beyond the technical and design features of the system under study, PosterVote raised questions related to the governance and ownership of the data collected and the influence of activists groups on the way people voted. In their work on crowdsourced cycling data, LeDantec et al. [12] noted issues of the provenance, legibility and meaningfulness of data generated by publics to those making planning decisions. Taylor et al. [43] —also raising issues of who owns and accesses communitygenerated data-note the ways in which residents make data meanigful by placing it into context. They also note the important role the research team played as a percieved neutral party to support dialogue and sensemaking around community-generated data, as well as providing the necessary skills and expertise to install and maintain devices and related infrastructures and archives. This is echoed by [44] who discuss the critical importance of building relationships with local residents and lead community members through the duration of projects and ensure skills and infrastructure are in place to sustain endeavours beyond the completion of the research project. In a similar vein, Hosio et al. [27] discuss the percieved value of situated displays in civic and community contexts, highlighting the range of additional costs and burdens they bring to the local government organisations who use them.

These examples in different ways pose questions about the responsibilities of different stakeholders in civic technology contexts where decision-making is a primary concern. They also raise issues related to the role of the researcher in these contexts, and whether they have a responsibility to not just to provide new tools with which to consult but also help organisations and individuals develop the skills, resources, capacity and practices to use these in a meaningful and sustainable manner. We build on the above by discussing our experiences of conducting field trials of distributed, multi-site community consultation technologies with two communty organisations. These deployments were intended to be led by our partners, as we will highlight, however, our community partners faced a number of conceptual and practical challenges in planning, overseeing and making sense of the insights from these deployments. Through our discussion of these projects we will highlight the ways in which the research team played an important role in carefully guiding and, at times, explicitly directing and managing parts of these deployments.

\section{OUR CONTEXT}

Our work built on the prior work of Taylor et al [45] and their original Viewpoint system. In the following, we provide an overview of this original work, followed by how our projects and version of the technology builds upon it.

\section{Viewpoint and the Bespoke Project}

The original Viewpoint technology was developed as part of the Bespoke project. The overarching project explored issues to do with community cohesion and political disengagement in a small city in North West England. Viewpoint allowed local councillors and community 
organisers to ask simple questions with binary answers (e.g. Yes/No or Agree/Disagree), with a new question appearing on the device each week. Each device had a display showing the question and two large, tactile buttons for voting. A rotary control allowed residents to scroll through previous questions to view the result and a statement explaining what would be done in response to the result. Three Viewpoint boxes, each networked and sharing the same questions and results, were deployed across the community in a local shop, a community centre and the offices of a housing association.

As noted in [45], the choice of a simple interface situated in a public space proved to be successful in gathering high quantities of feedback. Across a two-month deployment, eight different polls received an average of over two hundred votes each, an order of magnitude higher than original expectations. However, Viewpoint was less successful in creating the kind of positive feedback loop that had been intended. Community members remained sceptical of whether any change would occur, and few meaningful responses or promises of action were given by the local government collaborators. Having to work closely with councillors to help them formulate a question that was capable of being answered through a binary choice, the rapid turnover on questions, and the lack of actionable issues with a burning need for input made this difficult to achieve. As since discussed extensively by Harding et al. [26], this exposed a failure to integrate with existing council processes that might have created avenues for change. This was compounded by the way that Viewpoint placed the agenda firmly in the hands of those in positions of power, with community members acting as passive respondents.

\section{From Viewpoint 1 to Viewpoint 2}

Findings from the original Viewpoint suggest a number of future possibilities that we chose to take forward. First, the use of short-term, targeted deployments would allow the device to be deployed only when specific input was needed and actionable. This might also take advantage of the novelty effects that had been observed. Second, situated voting technologies might be more closely tied into existing practices. This could mean integrating with council feedback schemes, but it may also mean putting Viewpoint in the hands of community organisations who are already engaged with local authorities. For the most part, this repositioning only requires a change in how the device is used. However, to better support new deployment contexts, we redesigned Viewpoint with a focus on flexibility and portability. The redesigned device (Figure 1) allowed greater flexibility in how questions could be presented and responded to. It made use of a physical rotary control rather than buttons to allow voters to respond through multiplechoice answers or points on a sliding scale. It also supported voice and video input if required, along with a touch-screen display to be enabled as and when deemed appropriate. Additionally, the devices were made considerably smaller, with the intention that they might be

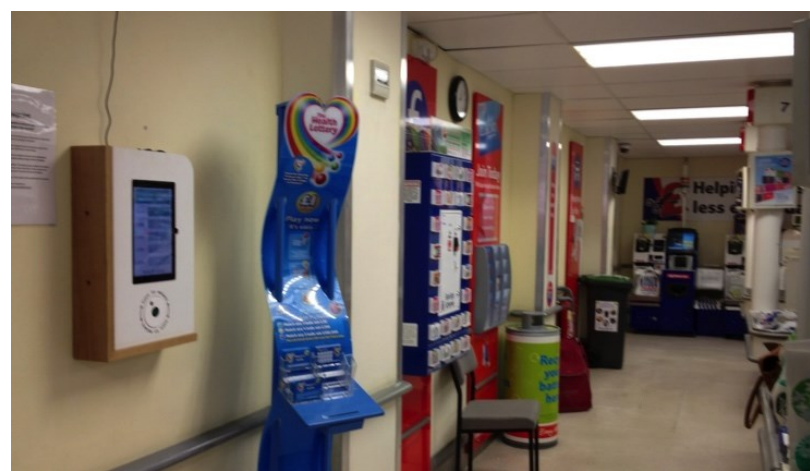

Figure 1. The second generation of Viewpoint while deployed at a supermarket for the Acorn Road case study.

more easily moved between different locations, and a $3 \mathrm{G}$ modem was added as a backup in situations where Wi-Fi could not be provided.

We deployed the second generation of Viewpoint in two case studies, where the technology was used by community groups to elicit feedback on issues related to local planning and transportation developments. In the following sections we provide an overview of these case study contexts.

\section{Case Study 1: Acorn Road}

Our first case study involved working with the local chapter of an international movement that champions sustainable communities. When we approached them, the group were beginning to collect evidence to support the pedestrianisation of Acorn Road, a small shopping street that formed the centre of their neighbourhood. The group felt that the street was overly congested, making it dangerous for local pedestrians and cyclists who they felt most used the street, and that many of the cars could easily be re-routed to create a more pleasant environment.

The campaigners used the Viewpoint boxes to contribute to their ongoing consultations with people on Acorn Road. They developed two questions (discussed in the Findings) that were displayed on the devices for two weeks each, during the summer and during the autumn (to collect data from the student population). Three devices were deployed in the community: two in local supermarkets, with a third inside the neighbourhood's library. Simultaneously, the group carried out a street survey in which they stopped passers-by to ask a number of questions, one of which related to means of travel, and a traffic observation survey. Across the entire deployment, shoppers placed 2,040 votes in total. By contrast, the group's past attempts to collect feedback online had returned only a few dozen results.

\section{Case Study 2: Ambit}

Our second study was conducted in a small coastal town in Northern England comprised of approximately 6,000 residents. The town attracts large numbers visitors in the summer season and is currently experiencing major redevelopment, particularly in its harbour area. Beside this regeneration, which is primarily funded by the local 

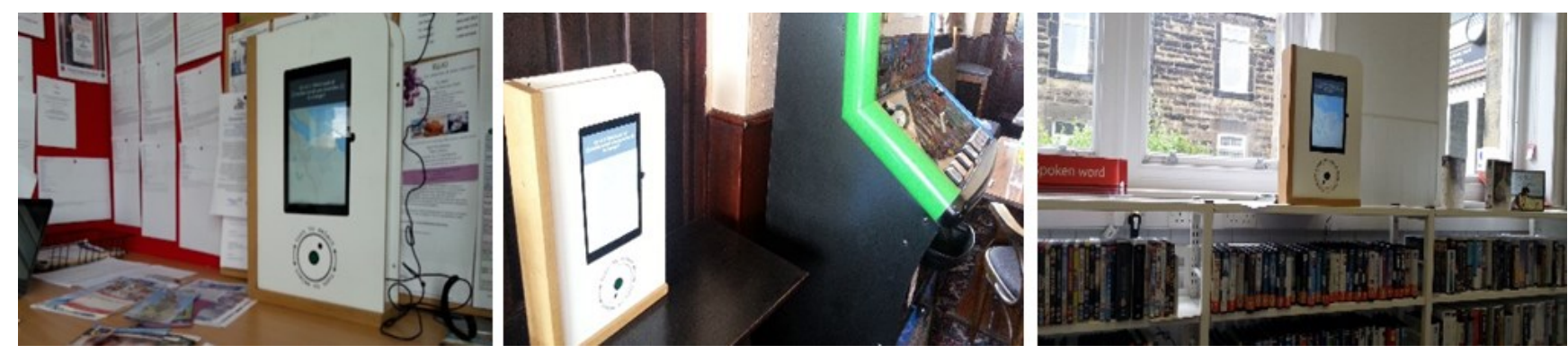

Figure 2. Viewpoint in different locations during the Ambit case study.

government, there is significant private investment. The development within the town is primarily driven by a Local Development Trust (henceforth 'the Trust'). The Trust was set up two decades ago as a response to the perceived lack of opportunities for development and employment in the town. It is responsible for attracting funding grants for community projects. One requirement the Trust has is to carry out public consultation as part of its applications to receive grants, along with further consultation to then allocate the budgets associated with community projects.

Significantly, there is a feeling amongst many residents in the town that regeneration is often focused on tourism, excluding the needs of those who live there. This is further compounded by high-levels of unemployment and closure of local industry over the last several decades. As such, this has led to a lack of trust that local and central government will act in their interests. These issues were echoed by the Trust, which has noted a substantial decline in levels of engagement in recent years which they put down to a feeling of disfranchisement from some residents. This is problematised further by a feeling that the consultations they perform tend to attract the same group of people every time, and the setting of consultation events at a fixed time and place leaves many people unable to attend.

These were important motivators for the Trust in using Viewpoint devices in their application scoping and project allocation processes. They developed three questions (again, discussed in the Findings) that were displayed on four boxes during the summer of 2015. Four devices were deployed in different locations around the town in areas where they expected to capture feedback from local people who would normally not engage in their consultations. Across the deployment of the Viewpoint devices, people registered 699 responses in total, with a significant number of these votes coming from devices located in parts of the town rarely engaged with by the Trust.

\section{METHOD}

Initial contact with each group came via community engagement activities conducted by our research lab. The research team then met with each of the organisations to discuss their projects, modes of engagement and consultation, and the challenges they faced.

During the Acorn Road deployments, the devices and the progress of the campaign were monitored by both a researcher and the campaign group, although the primary source of data collected was automated interaction logs. The researcher and campaign group maintained regular contact through the deployment. For Ambit, we expanded on this approach to place more focus on in-situ observations. Semi-structured interviews were conducted with four 'custodians' (people working in locations where devices were deployed). These interviews were audiorecorded and focused on the use of the device by others as perceived by the custodians. These were supplemented by observations where the researcher would 'hang around' [48] and note interactions with the device and events that occur in these spaces. The researcher talked with users of the devices to ask them about why they participated and their response to the ongoing results presented on Viewpoint. Overall, 84 hours of fieldwork observations were conducted and 22 conversations documented.

Each trial ended with a semi-structured interview with the representatives of each community partner, as well as device custodians for Ambit, where we discussed consultation results and how they may use the data gathered. The data collected (transcriptions of interviews and field notes) was then used as a corpus for thematic analysis $[3,9]$. Data coding was driven by questions related to how choices and decisions that impacted on the consultation process were made during the projects. Coding of data was shared between the first and second authors and checked by the third author. Codes were then clustered into the themes presented in this paper.

\section{FINDINGS}

Our analysis generated five themes. We organise our themes to present a comparative narrative of how the two field trials played out over time.

\section{Asking the Right Questions}

A critical aspect of our engagements across each study was working with the community organisations to establish the types of questions to be posed on the devices. Learning from our prior projects with the older Viewpoint boxes, each of our case studies was tied in one form or another to pre-existing campaigns and consultation processes. However, the stages within these processes at which the Viewpoints were used were rather different-this shaped the discussions around what questions may be asked, and how they should be asked and responded to. As such, what 
was initially assumed to be a simple endeavour in setting questions to ask the public, became complex decisionmaking processes in their own right.

In Acorn Road, the choice of overriding topic was determined by the pre-existing campaign. As noted, the ambitions behind the campaign were to advocate for the pedestrianisation of a local street. Initially the organisation considered using Viewpoint to directly ask residents whether they thought the street should be pedestrianised, with the intention that this could be presented to the council like a petition. However, prior to deployment concerns were raised about this direct line of questioning:

"At first we thought we'd do a poll, "Are you in favour of pedestrianisation", but [...] what would that mean? It might mean different things to different people and it also might lead to resistance and people would be saying, oh well come out and vote against it and it wouldn't really be a very easy thing to get a fair result from." (Acorn Road campaigner)

This was a concern raised all the more by the fact that local businesses - who were opposed to pedestrianisation-were envisaged as being the most likely deployment locations, so some sensitivity was required. Instead, the group developed a new set of questions and possible responses that, as they articulated it, were more "objective" (Acorn Road campaigner). Two questions were asked: "What has been your main means of travel today?" followed by "How far do you live from here?" These questions sought to ascertain what percentage of the street's users were travelling by car and what proportion were local and might reasonably travel by foot or bicycle instead. The questions themselves were carefully chosen and reflected the many stakeholders that existed in this community issue. The decision to collect "objective" data about usage of the street rather subjective opinions about its future meant that data was felt to be unbiased (or, at least, less biased), and was envisaged as being taken more seriously by the complex range of actors involved in future decision making.

A similarly complex set of trade-offs around question setting occurred in the Ambit project. The Ambit project differed significantly from Acorn Road in that it occurred at a much earlier stage in a consultation process. As such, there was not a specific campaign for the organisation facilitating the trial to push-rather the Viewpoint devices were to be used as part of a scoping exercise for future project development. The main ambition here was to capture views from people about the locations and places in the town they felt needed investment. This initial broad consultation process would identify specific locations in the area to be targeted in a more focused piece of consultation work. Like Acorn Road, however, the language used in the questions posed was very carefully considered. While the Trust did have money for projects, they "did not want to raise expectations" (Trust representative) that this scoping process would lead to money being committed before current projects were complete. Initial questions suggested for the devices included words such as "funding", "investment" and "projects"-however, these were iterated to instead focus on the locations in the town people wished to "change" or where they "like to visit". These changes to how the questions were posed made them much more ambiguousat the same time it allowed the Trust to distance themselves from acting on the results of the consultation, should they feel unable to commit to working in the locations most identified in the responses.

Across both deployments the community groups had an agenda that in some way they wanted to obfuscate. As researchers, we had to find ways to fulfil the broad goals of each consultation, yet also encourage flexibility against some of the more conservative plans for using the technologies made by the community organisation. This continued when designing how citizens would respond to the questions posed on Viewpoint, which we discuss next.

\section{Considering Forms of Response}

While in both studies the same system was used, the process of providing responses to questions was very different. The way in which people were invited to respond represented the types of questions our collaborators defined and, again, the stage in their consultation process they found themselves to be in. In Acorn Road, the campaign group were very clear about the form of data they required and, as noted, had a strong desire for it to look objective. It needed to carefully compliment previous surveys they had conducted, and the data was to be used in a public report handed to the local council. The campaigners had a preference for collecting detailed information using a multistage questionnaire presented on Viewpoint. Ultimately, they had to be convinced by us that this was at odds with the design intent underpinning Viewpoint - that it offered lightweight and quick engagement - and that based on previous work it was unlikely people would stand and complete a longer questionnaire in a public place. This demonstrated a tension between the insights gained from our previous research experience and their desire for it to fit in with familiar frameworks of data.

The process of determining the form of response was rather more complex in Ambit, perhaps in part due to the scoping nature of the Trust's exercise. Initially, much like the campaign group, the organisation envisaged appropriating Viewpoint in relation to traditional consultation methods. They imagined using the box as an "interactive questionnaire" (Trust representative) where passers-by could switch through different questions and respond to them through scaled answers. However, when iterating imagined answers to these questions it was thought such an approach would lead to a very restrictive set of responses. Through a series of meetings, we came to an agreement that the Viewpoint boxes should represent the local area cartographically, where respondents could simply touch those parts of the town that correspond with their response to the question. Again, however, this process was not as 
simple as may appear - there was anxiety among the Trust that capturing just a location on a map was "not enough" and that they needed to "know more" (Trust representative). There was a desire to capture additional comments from people who provided their response to the question. Ideas suggested at this stage included supporting video or audio feedback via the cameras and microphones built into the system. These were discounted by the Trust however due to perceived privacy concerns.

The issues encountered in both of the projects around defining the ways people responded to consultation questions highlighted issues around the legibility of even relatively simple civic technologies to community groups. Furthermore, it highlights the significant agency the research team had in advising and, in some respects, pushing ideas around what the technology was for and how it would best work. This is an issue we return to in more detail in the following section.

\section{Locating the Devices}

Through the two projects, the Viewpoint boxes were deployed across seven different locations for at least twoweeks at a time. Strategic selection of locations was important in both of the projects. Prior to each of the projects, it was assumed that good places for locating these boxes would be busy places. For the campaign group there was a concern for making sure the Viewpoint boxes were placed in carefully chosen locations in and around Acorn Road where they captured "a lot of footfall" but also a broad audience of passers-by. Two of the devices were located in local supermarkets - one a branch of the country's largest retailer and the other a newly opened branch of an upmarket chain. Both shops were heavily trafficked and the location of the devices, both just past the check-outs (see Figure 1), helped to secure a large number of votes. In the Ambit project, the Trust wished to locate one of the boxes in a newly opened seafood centre, where again it was assumed they "would get a lot of people coming" (Trust representative). Indeed, these assumptions were confirmed as the seafood centre did capture the largest number of responses overall. The other locations where the devices were deployed blurred notions of public and private. In both projects, local libraries were used as locations for a device. Libraries were chosen as a legitimate space for the type of consultation processes both groups were engaging in-indeed, historically libraries in the UK often act as venues where redevelopment plans are displayed. Unlike shops and busy tourist destinations, libraries are also almost exclusively used by local residents, which has implications in terms of demographics that can be reached. In both projects, libraries were the locations with the fewest responses, yet they were appreciated for being able to reach parts of the community busier locations might not.

Another location used in the Ambit project was a local pub. Like libraries, community pubs are almost exclusively used by local residents, and they are places that have a unique social mix, considered to contribute to social capital and a healthy community [36]. Pubs are places void of institutional influence where citizens share information, often through vernacular, rather than formal interactions, but this sharing is a by-product of the focal activity of socialisation $[17,18]$. While this may appear to be an unorthodox location for these devices, it was chosen due to being embedded in a different part of the town to the other devices in Ambit. We also assumed the chatter, gossip and complaints that may occur in such spaces might be usefully harnessed for the purposes of the consultation. During the deployment, the pub received the second highest quantity of responses - this was despite being deployed for the shortest period of time. More significantly, however, votes made at the pub were dramatically different to the three other locations in Ambit. In response to the 'place you would change' question, places where factories had closed down and job losses occurred were dominant. Our interviews and observations highlighted how bringing a Viewpoint to this location engendered conversations - and that the space was formed of regulars and hangers-around meant discussions were deeper and more heated than the impromptu and fleeting conversations seen at the other places the boxes were located.

It's worth noting that in all cases gaining access to the 'right' locations was not a simple affair. In the Ambit project a key criteria for the Trust was to elicit feedback from people who were not the "usual suspects". One of the core benefits seen in using the Viewpoint boxes was that they could be situated around the town in different locations, perhaps where dwellers and passers-by might not be those who would normally interact with the Trust. However, while the Trust desired to connect with the wider community, they were limited in brokering locations where the devices could be located. Indeed, early in the project, suggested locations were primarily based on their existing social networks. While in many cases the proprietors of these venues were happy to engage, the locations were not fitting with the stated aims of the consultation.

Again, the research team found themselves conflicted in the Ambit collaboration - should we let the Trust continue in their planned process of consultation, or should we push back and direct them to using other locations? It became clear at this stage that our collaborators simply did not have the social capital within the town with which to access certain places. What then followed involved the lead author taking ownership of a small number of boxes as a seemingly neutral party, in an attempt to engage new stakeholders across the town in the project. This process of wider engagement was, in itself, an incredibly time consuming and intensive process. It literally involved the researcher walking from one end of the town, visiting venues, and if appropriate spending time in each, before approaching staff or managers to explain the project, often with positive and supportive reactions. 
Overall, the locating of the devices for the Acorn Road project was a simpler process - the campaign group used their existing links with local supermarkets and the local council to have the boxes installed. However, the ease of gaining initial consent masks a variety of issue that needed to be taken into account: health and safety regulations, pressure from managers regarding the appearance of a store, and local politics. As previously discussed, the choice of location even influenced the questions that could be asked, as it became increasingly important not to alienate traders who were also hosting the devices. These were issues experienced in Ambit as well, where despite the initial good will reported above, sometimes practical and infrastructural problems in specific shops, cafes and pubs meant Viewpoints could not be installed.

\section{Making Sense of the Data}

A further set of issues encountered during both studies related to the expectations our collaborators set around the value and validity of the data they would be collecting, and how they were able to use this going forward. In the case of the Acorn Road deployment, there was a very clear trajectory for the organisation from the collection of the data through to presenting it to the local authority alongside data collected by traditional methods. The Viewpoint devices were unique in capturing data over longer periods of time, while expending less human resource from the campaign. That the types of data collected were comparable to one another was of huge value here. On its own the data from Viewpoint wasn't seen as entirely "legitimate", but as one feature in a set of tools it was seen to be "very useful" (Acorn Road campaigner) in gathering a wider picture of the issue at hand. This was aided all the more that many of the results were "as expected":

"I think that was what I expected, I mean I suppose I might have hoped that it would have been only $10 \%$ car, but that would have been very unlikely considering how many cars go up and down. So I think it was really matched pretty much with what I did expect." (Acorn Road campaigner)

In particular, the campaign group felt the devices validated their intuition that more people travelled via public transport to the local area, and that the majority of shoppers were likely to be students:

"The findings [...] from the Viewpoint [show] that the majority of people come by foot or bicycle or public transport depending on the time of year. But during the student time it's more, and that's most of the year actually." (Acorn Road campaigner)

This is not to say that the trial did not process some unexpected results. One of the results that did surprise the campaigners was that despite a significant number of people travelling by car, the vast majority travelled from less than three miles away:

"But I was surprised at how many people came from so close [...] about 75\% were less than 3 miles [...] I didn't think it would be as high as that. So they [cars] are very locally used." (Acorn Road campaigner)
This specific insight from the Viewpoint deployments was particularly significant for the campaign group in their work going forward. While many of their assumptions had been verified, this new layer of insight meant aspects of their argument had to be readdressed:

"The traders rightly said they do have people coming from outside the area too, and obviously part of the 25\% come from more than 3 miles away. But they are basically used by local people so [...] I think it's very unlikely that you'll put off local shoppers who are going to come anyway." (Acorn Road campaigner)

In making sense of the data, the campaign group were not only forced to readdress their assumptions, but also change the focus of their campaign - softening their plans for full pedestrianisation, to a semi-pedestrianised space that still acknowledged the need for some parking and other access.

Compared to the Acorn Road campaign, the Viewpoint data in Ambit was somewhat more challenging for the Trust to make sense of. This was, in part, a result of the more ambiguous framing of the questions and the form of response determined at the start of the project. When reviewing the data the Trust representatives initially struggled to interpret what was before them: "I don't understand why they would choose that place". This led to questioning the validity of responses: "that's just someone pointing to their house". As this sense-making continued, rather than using the devices as a means to identify areas for the focus of future work, the data started to be used as a way to reaffirm assumptions and preconceptions of what people from certain parts of the town would feel is most important:

"See I wouldn't expect someone to come here and know that we're desperate to get some employment created up on the industrial estate, and that's what the majority of people in [the pub location] would say, I think." (Trust representative)

In this case, contributions on Viewpoints located where there would likely be many tourists were interpreted, perhaps unsurprisingly, as highlighting places that were primarily visitor attractions. Locations identified on boxes in primarily residential areas - such as the pub-instead were contextualised in the history of the town and ongoing concerns around employment opportunities. The data was used to construct a narrative about the different priorities people who used Viewpoint would have. These narratives were often based on ideas of who was living in specific parts of the town, what their imagined concerns and aspirations were and why they would choose specific places to change. Because the Viewpoints had not captured the provenance of these responses, the Trust's representatives made sense of these through relying on their own prior assumptions and knowledge.

While much of the data was used to reinforce what was already 'expected' by our partners - for Acorn Road judgements were made about the mode of travel of shoppers; for Ambit this was much more determined by the 
imagined social class and background of the people responding in a particular place - it did leave space for ambiguity and interpretation, and even the groups reassessing their interpretations.

\section{Discussion, Decisions and Divisions}

Throughout both of the studies, the Viewpoint deployments caused a significant amount of discussion and debate. This was somewhat a novelty effect - across many of the periods spent observing Viewpoint at a distance, members of the public would be seen staring at it, asking questions of staff in venues about what it was, what it was doing here, and how to use it. The leader of the campaign group noted that "it stimulated discussion, for sure" and that people "asked what's going to be done". All of the custodians interviewed at the end of the Ambit project reported how conversations that were born from curiosity typically then opened a debate about specific issues around the places displayed on the devices. In some cases these individuals saw it as a catalyst to discuss wider issues and in turn contest future decisions:

"I say it's been a talking point and it's getting everyone talking, and involved in a conversation, about what their favourite parts of [the town] are, what they would change, erm, we've had some gripes, we've had some great ideas. [...] if someone wanted to challenge a decision, it would give them access to data that states look, 'this is what we want' this is, is a community project, the community answers." (Ambit custodian 4)

Custodians of the devices also explained how people that may not normally be engaged in such processes were seemingly empowered by the boxes. For instance, our custodian in the public house explained how many people she knew well, but rarely discussed politics with, were suddenly inspired to comment on recent redevelopments based on the presence of the Viewpoint box. She remarked in surprise that older, opinionated, but "technophobic" regulars were seen to participate in giving their response. Another one of the locations hosting a device in Ambit regularly runs training sessions and courses for young people. The assumptions of the custodians in this space was that such a group would be reluctant to get involved in activities beyond their own training: "But they actually took part... which they wouldn't have done if we'd asked them direct." (Ambit custodian 1).

Clearly, the hope of promoting discussion and gathering data, from our collaborators perspectives, was to inform either their own decision making, or to put pressure on and influence the decisions of others. In Acorn Road, the Viewpoint consultation was a key step in a much longer process. Combined results of the Viewpoint survey and a street survey asking similar questions were presented to the city council as a report. The group's recommendation was softened based on the results, from full pedestrianisation of the street to a one-way street with shared space for cars, bikes and pedestrians. What followed was a period of consultation and protest lasting three years. After proposals were unveiled, local businesses complained about the loss of parking spaces, leading the council to launch a consultation on two different proposals. After the more radical proposal was chosen, concerns were raised about the validity of the vote and who was able to contributeconcerns that are echoed in our own findings around Viewpoint, which on its own lacked legitimacy. Interestingly, part of this consultation took place through the city's recently-launched online consultation platform, as well as through more traditional means. Two further petitions - one from each side of the argument-led to a reopened consultation and a revised plan that retained more parking spaces. At the time of writing, work is just beginning on the site, three years after the Viewpoint data was collected. Despite Viewpoint's role being dwarfed by the scale of the process, it is notable that there were clear points where Viewpoint and other technologies empowered citizens to drive or shift the agenda. There was similar hope that the Ambit deployment would also lead to some decision being made-even if this was just to determine more focused consultations in the next round. However, the discussions promoted around Viewpoint were in many respects born from a suspicion of the local council, or of those running the consultation. For example, early in the deployment one of the custodians commented on how some people were suspicious of places "missing" from the maps on the devices:

"People asked where places were, they were concerned about as they could not identify them on the map, so they had these preconceived ideas already [of deception and mistrust] and saw this as an opportunity to say something." (Ambit custodian 4)

Fears were raised that places that were missing had already been determined as not worthy of changing. Furthermore, as time went on, the data being captured by the Viewpoint boxes themselves appeared to reaffirm these divisions within the town: different Viewpoint sites captured very different impressions of what were important places to change; these would then be viewable and made visible to people interacting with the devices; this, in turn, promoted even further discourse around mistrust and division in the town. Critically, the Trust themselves - and not just local governors - were open for critique. They were described as a "very closed group", and indistinguishable from other institutions of power in the town: "the same people's on the development trust's as is on the harbour commissioners; they've all got their finger in little pies." (Ambit custodian 4). The lack of visibility with what was happening to the data they collect, coupled with the feeling some groups are excluded from any development has left people concerned about whose interests are being served.

The community groups in our studies were sometimes discussed as an extension of the civic authority, warranting the same distrust. Despite the studies being designed to support consultation, there were many unexpected results around broader issues of division and decision-making that were equally, if not more, interesting. 


\section{DISCUSSION}

Our two case studies highlight some of the challenges for researchers and community organisations engaging in the use and deployment of situated consultation technologies. Some challenges were practical and technical in naturesuch as gaining access to appropriate locations that had the required space and infrastructure for the boxes to work, but most were conceptual, social and political. In the following sections we examine some of these issues. We draw out a number of key reflections on our experiences with Viewpoint and ask questions for the HCI and civic technology communities going forward.

\section{The Researcher as an Agent}

One issue that was apparent in both of the case studies was the important role the researcher plays as an agent and as part of the infrastructure of civic technology deployments. There is very often a tendency for the voice of the researcher to be 'written out' in the aid of objectivity, a criticism that HCI scholarship has faced in recent years $[1,7]$. In our case it would be impossible not to acknowledge how critical the research team were in shaping the work conducted. We acted as critical friends to bounce ideas off-helping our collaborators to think through the questions they wished to pose, the places they wished to pose them in, and supporting them in understanding the particular affordances offered by the boxes. On other occasions we were more direct in our guidance. This was, we felt, to ensure that they maximised the potential of the technology. However, with it we also invoked a particular stance on what we saw as the 'right' and 'wrong' way to motivate people to participate in local decision making.

The participatory research literature highlights the importance of capacity building [29] and the negotiation of power and control in community research contexts [10]. In our examples we could see how a mutual exchange of skills and expertise informally supported the development of reflective practices around setting questions and inviting responses. Control over this had to be continually negotiated however, and a balance had to be found between offering our expertise and not taking ownership of the consultation. Often community partners have more at stake and more to lose than the research team, so in our case it was not surprising they resisted some of the ideas we brought. At different moments the social capital of the researchers or the community groups was more appropriate, and understanding this dynamic was an important element in maintaining positive and successful partnerships. Greater honesty and critical reflection on these issues is therefore needed, not just in civic technologies research, but in a broader range of participatory projects in HCI where such issues might arise.

\section{The Mess of Making Decisions}

The rhetoric underpinning much of the civic technology and digital democracy literature is that digital systems can support new relationships between citizens and states (e.g. $[21,41])$, and provide new mechanisms for decision-making (e.g. $[19,31,37,38,40])$. In many respects it was this rhetoric that motivated our collaborators' use of the Viewpoints. In using the devices, both hoped to come to some agreement about the issues that faced them, to determine what 'should' be done about a busy road, or where the focus 'should' be of future community projects. However, in practice the results of both case studies raised more questions than answers. In the case of Ambit there were some occasions where people at different sites found commonalities with the views seemingly expressed elsewhere. Primarily however Viewpoint provided a platform for community members to express their concerns around the ongoing regeneration of the town, and a recent history of political dissatisfaction and economic disadvantage. The maps on the devices made visible social divisions and perceived and actual inequalities within this small community. In the Acorn Road trial the questions raised by the system were perhaps less divisive but equally as complex to deal withthey required the campaigners to re-evaluate their own perceptions of the problem at hand, to soften their political stance, and to find common solutions to the very different challenges and positions of a myriad of stakeholders.

Viewpoint was somewhat predicated on the idea that technology can provide lower barriers of entry to having a say and thus support the conditions for democratic processes to occur. This simplistic view ignores how such interventions fit into the much wider, complex network of processes and actors of varying degrees of power and influence at play. It also ignores pre-existing issues around trust between different parties, an issue that has been argued to be oft-discounted in digital voting and consultation literature [33]. As noted by Harding et al. [26], this is not just mistrust of decision-makers and authorities by certain groups of citizens, but also mistrust from certain decisionmakers as to the legitimacy and value of contributions in certain formats or from specific groups of people. In our case it was clear that Viewpoint in some cases reaffirmed these issues of mistrust. Perhaps revealing these issues could be productively channelled in the long-term, but only if technologies like Viewpoint are designed in ways to account for this bigger picture and embedded as an actor in a carefully designed process of decision-making.

\section{Ownership, Power and Feedback}

As with prior work $[12,43,47]$ our studies also raised questions around who owned the data generated by the Viewpoint devices, and the subtle ways ownership and power over the data were deployed by our partnering organisations. Burgess [4] warns that the ongoing appropriation of deliberative engagement by institutional authorities can often serve to legitimise policy decisions set independently of public participation. It would be unfair to claim that this was the case in our studies - there was great will and desire from both of our partners to reach into new parts of the community, to consult a wide number of people, and to use the insights gathered in a meaningful and honest manner. However, because both of the projects had 
very specific agendas involved it was hard for our collaborators not to let these shape the ways in which the consultations with the devices happened.

One observation here is that our desire to seek case studies where there were the results would the "actioned" (at least envisioned to be) meant our partners very carefully thought through the types of questions they would ask. While in part this was a process of ensuring they would ask good quality questions, as we saw it also involved them thinking through the potentially negative consequences of asking the wrong questions. In Ambit, the wrong question was one that would be seen to commit the Trust to spend project funds on a particular site in town; for the campaign group it was to make known their own values and opinions from the consultation. It could be argued that by choosing not to expose their ultimate intentions, the campaign group prevented citizens and local businesses from making their voices heard. We can imagine that these other stakeholders might want to collect their own data if they are in opposition to those conducting the polls, or to verify the data being collected; indeed, this was a desire and even an expectation expressed by the custodians of our devices in the Ambit project.

That the systems were deployed in clear decision-making processes also raised further questions around power, the use of citizen voice, and potentially on efficacy. Where the first generation Viewpoint device was designed with inbuilt mechanisms to support accountability and a sense of efficacy, the timescales and number of actors involved in these actionable contexts make this impossible. The slow timescales of decision-making processes and eventual outcomes are juxtaposed sharply against the quick, straightforward, lightweight interactions afforded by civic technologies, leaving a gap between engagement and action that may cause citizens to question 'what' is happening with the data. Fundamentally the length of these consultation processes means the rhetoric around feedback and voter efficacy become highly problematic.

\section{CONCLUSION}

In this paper we have reported on our experiences of working with community organisations that used our distributed, situated technologies as platforms for consulting their local communities. We have highlighted the diverse ways the Viewpoints promoted discussion and debate, facilitated the making of decisions, and exposed mistrust and contestation in the places they were deployed. In some cases this was promoted by the fact the boxes were installed in highly public locations, seen and engaged with, by a large number of people; it was also because they were distributed in a range of other locations as well, where existing practices of sociality and conviviality could be harnessed further. This is in keeping with recent work on similar systems (e.g. [28]) that highlights the potential of these technologies to create a buzz and dialogue around local matters of concern. It also overlaps with scholarship on deliberative democracy [16,32], which states that political discourse are acts of everyday talk, and we should take the processes of decision-making to those sites where such talk occurs in civil society [35].

However, it's critical to note that while we (the researchers) captured the buzz around the deployments, our collaborating community partners did not. The design of Viewpoint was such that it followed a simple framework of participation in the aid of lowering the barrier to entry. In doing so it purposely designed out the collection of "noise", privileging the idea that participation in local matters of concern can be captured at the press of a button or the tap of a map. If it were not for the performance of fieldwork around our systems then the richness and detail of conversations would be missed. While this may appear to be a moot point, it's a critical one in a context where the ambition is to create platforms that enable people to ask questions of others. In this context, it is critical to understand 'why' people say what they do, and to capture the wider discourse the questions posed provoke. Such additional layers of study would be practically difficult for our collaborators to conduct. Further, the perceived lack of objectivity of our collaborators from some of those being consulted may, in some respects, have made any such attempts meaningless. In this regard, the perceived neutrality of the researchers [43] eased people into sharing their views in a more candid manner.

One might argue that there were opportunities in our work to design in the capturing of such 'noise'. We could have invited people to give video or audio responses to questions. But beyond the privacy concerns bound up in this, there is a more poignant concern that such interactions lose the richness and discursive, dialogic element of debate. In future work, we should perhaps look to designing systems that adapt to the conversations already taking place in society, rather than asking citizens to adapt to artificial interactions to express their views. With this comes an appreciation that it is the researcher's duty to proactively capture and convey this richness, so that community organisations - and the authorities and institutions to which they lobby - can acknowledge and use them appropriately in their decision-making processes.

\section{ACKNOWLEDGMENTS}

We'd like to thank our community partners and the Viewpoint 'custodians' for giving their time to these projects. This research was funded through the EPSRC Centre for Doctoral Training in Digital Civics (EP/L016176/1) and EPSRC Additional Sponsorship for Newcastle University (EP/J501359/1). Data supporting this publication is openly available under an 'Open Data Commons Open Database License'. Additional metadata are available at: $10.17634 / 154300-8$. Please contact Newcastle Research Data Service at rdm@ncl.ac.uk for access instructions. 


\section{REFERENCES}

1. Mara Balestrini, Jon Bird, Paul Marshall, Alberto Zaro, and Yvonne Rogers. 2014. Understanding sustained community engagement. Proceedings of the 32 nd annual ACM conference on Human factors in computing systems - CHI '14, ACM Press, 26752684.

http://doi.org/10.1145/2556288.2557323

2. Peter van den Besselaar. 2005. Communities and Technologies 2005: Proceedings of the Second Communities and Technologies Conference, Milano 2005. Springer Science \& Business Media.

3. Virginia Braun and Victoria Clarke. 2008. Using thematic analysis in psychology. Qualitative Research in Psychology 3, 2:77-101.

4. Michael M Burgess. 2014. From "trust us" to participatory governance: Deliberative publics and science policy. Public understanding of science (Bristol, England) 23, 1: 48-52.

5. John M. Carroll, Michael Horning, Blaine Hoffman, Craig Ganoe, Harold Robinson, and Mary Beth Rosson. 2011. Community Network 2.0: Visions, Participation, and Engagement in New Information Infrastructures. In End-User Development, Maria Francesca Costabile, Yvonne Dittrich, Gerhard Fischer and Antonio Piccinno (eds.). Springer Berlin Heidelberg, Berlin, Heidelberg, 270 - 275.

6. John M. Carroll and Mary Beth Rosson. 2007. Participatory design in community informatics. Design Studies 28, 3: 243-261.

7. Alan Chamberlain, Andy Crabtree, and Mark Davies. 2013. Community engagement for research. Proceedings of the 6th International Conference on Communities and Technologies - C\&T '13, ACM Press, 131-139. http://doi.org/10.1145/2482991.2483001

8. Sandy Claes, Niels Wouters, Karin Slegers, and Andrew Vande Moere. 2015. Controlling In-the-Wild Evaluation Studies of Public Displays. Proceedings of the 33rd Annual ACM Conference on Human Factors in Computing Systems - CHI '15, ACM Press, 81-84. http://doi.org/10.1145/2702123.2702353

9. V. Clarke and V. Braun. 2013. Teaching thematic analysis: Overcoming challenges and developing strategies for effective learning. The Psychologist 26, 2:120-123.

10. A Cornwall and R Jewkes. 1995. What is participatory research? Social science \& medicine (1982) 41, 12: 1667-76.

11. Clara Crivellaro, Rob Comber, John Bowers, Peter C. Wright, and Patrick Olivier. 2014. A pool of dreams. Proceedings of the 32nd annual ACM conference on Human factors in computing systems - CHI '14, ACM
Press, 3573-3582.

http://doi.org/10.1145/2556288.2557100

12. Christopher A. Le Dantec, Mariam Asad, Aditi Misra, and Kari E. Watkins. 2015. Planning with Crowdsourced Data. Proceedings of the 18th ACM Conference on Computer Supported Cooperative Work \& Social Computing - CSCW '15, ACM Press, 1717-1727.

http://doi.org/10.1145/2675133.2675212

13. Christopher A. Le Dantec and Sarah Fox. 2015. Strangers at the Gate. Proceedings of the 18th ACM Conference on Computer Supported Cooperative Work \& Social Computing - CSCW '15, ACM Press, 1348-1358.

http://doi.org/10.1145/2675133.2675147

14. Christopher Le Dantec. 2012. Participation and publics. Proceedings of the 2012 ACM annual conference on Human Factors in Computing Systems CHI '12, ACM Press, $1351-1360$. http://doi.org/10.1145/2207676.2208593

15. Rogério DePaula. 2004. Lost in translation. Proceedings of the eighth conference on Participatory design Artful integration: interweaving media, materials and practices - PDC 04, ACM Press, 162. http://doi.org/10.1145/1011870.1011890

16. John S. Dryzek. 2000. Deliberative Democracy and Beyond: Liberals, Critics, Contestations. Oxford University Press.

17. Karen E. Fisher, Joan C. Durrance, and Marian Bouch Hinton. 2004. Information grounds and the use of need-based services by immigrants in Queens, New York: A context-based, outcome evaluation approach. Journal of the American Society for Information Science and Technology 55, 8: 754-766.

18. Karen E. Fisher and Charles M. Naumer. 2006. Information Grounds: Theoretical Basis and Emperical Findings on Information Flow in Social Settings. In New Directions in Human Information Behaviour, A Spink and C Cole (eds.). Springer, 93 111.

19. JS Fishkin and RC Luskin. 2005. Experimenting with a Democratic Ideal: Deliberative Polling and Public Opinion. Acta Politica 40: 284 - 298.

20. Sarah Gallacher, Connie Golsteijn, Lorna Wall, Lisa Koeman, Sami Andberg, Licia Capra and Yvonne Rogers. 2015. Getting quizzical about physical. Proceedings of the 2015 ACM International Joint Conference on Pervasive and Ubiquitous Computing UbiComp '15, ACM Press, 263-273. http://doi.org/10.1145/2750858.2807529

21. Björn-Sören Gigler, Samantha Custer, Savita Bailur, Elizabeth Dodds, Saher Asad, and Elena GagievaPetrova. 2014. Closing the Feedback Loop: Can 
Technology Amplify Citezen Voices? In Closing the feedback Loop: Can Technology Briidge the Accountability Gap?, Björn-Sören Gigler and Savita Bailur (eds.). The World Bank, 211 - 270.

22. Connie Golsteijn, Sarah Gallacher, Lisa Koeman, Lorna Wall, Sami Andberg, Yvonne Rogers and Licia Capra. 2015. VoxBox. Proceedings of the Ninth International Conference on Tangible, Embedded, and Embodied Interaction - TEI '14, ACM Press, 201208. http://doi.org/10.1145/2677199.2680588

23. Jorge Goncalves, Denzil Ferreira, Simo Hosio, Yong Liu, Jakob Rogstadius, Hannu Kukka and Vassilis Kostakos. 2013. Crowdsourcing on the spot. Proceedings of the 2013 ACM international joint conference on Pervasive and ubiquitous computing UbiComp '13, ACM Press, 753. http://doi.org/10.1145/2493432.2493481

24. Jorge Goncalves, Simo Hosio, Yong Liu, and Vassilis Kostakos. 2014. Eliciting situated feedback: A comparison of paper, web forms and public displays. Displays 35, 1: 27-37. http://doi.org/10.1016/j.displa.2013.12.002

25. Derek L. Hansen, Jes A. Koepfler, Paul T. Jaeger, John C. Bertot, and Tracy Viselli. 2014. Civic action brokering platforms. Proceedings of the 17th ACM conference on Computer supported cooperative work \& social computing - CSCW'14, ACM Press, 13081322.

http://doi.org/10.1145/2531602.2531714

26. Mike Harding, Bran Knowles, Nigel Davies, and Mark Rouncefield. 2015. HCI, Civic Engagement \& Trust. Proceedings of the 33rd Annual ACM Conference on Human Factors in Computing Systems - CHI '15, ACM Press, 2833-2842. http://doi.org/10.1145/2702123.2702255

27. Simo Hosio, Jorge Goncalves, Hannu Kukka, Alan Chamberlain, and Alessio Malizia. 2014. What's in it for me. Proceedings of The International Symposium on Pervasive Displays - PerDis '14, ACM Press, 174179.

http://doi.org/10.1145/2611009.2611012

28. Lisa Koeman, Vaiva Kalnikaité, and Yvonne Rogers. 2015. "Everyone Is Talking about It!" Proceedings of the 33rd Annual ACM Conference on Human Factors in Computing Systems - CHI '15, ACM Press, 31273136.

http://doi.org/10.1145/2702123.2702263

29. Ajit Krishnaswamy. 2004. Participatory Research: Strategies and Tools. Practitioner: Newsletter of the National Network of Forest Practitioner 22: 17-22.

30. Yu-Hao Lee and Gary Hsieh. 2013. Does slacktivism hurt activism? Proceedings of the SIGCHI Conference on Human Factors in Computing Systems - CHI '13,
ACM Press, 811.

http://doi.org/10.1145/2470654.2470770

31. Cristiano Maciel, Licínio Roque, and Ana Cristina Bicharra Garcia. 2009. Democratic citizenship community: a social network to promote e-deliberative process. Proceedings from the 10th Digital Government Society of North America, 25-34. 7

32. Jane Mansbridge. 1999. Everyday talk in the deliberative system. In Deliberative Politics: Essays on Democracy and Disagreement., Stephen Macedo (ed.). Oxford University Press, Oxford.

33. Viktor Mayer-Schönberger and Kenneth Cukier. 2013. Big Data: A Revolution that Will Transform how We Live, Work, and Think. Houghton Mifflin Harcourt.

34. Cecelia B. Merkel, Lu Xiao, Umer Farooq, Craig H. Ganoe, Roderick Lee, John M. Carroll and Mary Beth Rosson. 2004. Participatory design in community computing contexts. Proceedings of the eighth conference on Participatory design Artful integration: interweaving media, materials and practices - PDC 04, ACM Press, 1. http://doi.org/10.1145/1011870.1011872

35. Giles Moss and Stephen Coleman. 2013. Deliberative Manoeuvres in the Digital Darkness: e-Democracy Policy in the UK. The British Journal of Politics \& International Relations 16: 410 - 427.

36. Ray Oldenburg. 2001. Celebrating the Third Place: Inspiring Stories about the "great Good Places" at the Heart of Our Communities. Da Capo Press.

37. Jeremy Pitt, Lloyd Kamara, Marek Sergot, and Alexander Artikis. 2005. Voting in online deliberative assemblies. Proceedings of the 10th international conference on Artificial intelligence and law - ICAIL '05, ACM Press, 195. http://doi.org/10.1145/1165485.1165516

38. Bryan C. Semaan, Scott P. Robertson, Sara Douglas, and Misa Maruyama. 2014. Social media supporting political deliberation across multiple public spheres. Proceedings of the 17th ACM conference on Computer supported cooperative work \& social computing - CSCW'14, ACM Press, 1409-1421. http://doi.org/10.1145/2531602.2531605

39. Bryan Semaan, Heather Faucett, Scott Robertson, Misa Maruyama, and Sara Douglas. 2015. Navigating Imagined Audiences. Proceedings of the 18th ACM Conference on Computer Supported Cooperative Work \& Social Computing - CSCW '15, ACM Press, 1158-1169. http://doi.org/10.1145/2675133.2675187

40. Bryan Semaan, Heather Faucett, Scott P. Robertson, Misa Maruyama, and Sara Douglas. 2015. Designing Political Deliberation Environments to Support Interactions in the Public Sphere. Proceedings of the 
33rd Annual ACM Conference on Human Factors in Computing Systems - CHI '15, ACM Press, 31673176.

http://doi.org/10.1145/2702123.2702403

41. Lisa J. Servon. 2008. Bridging the Digital Divide: Technology, Community and Public Policy. Wiley, Hoboken.

42. Kate Starbird and Leysia Palen. 2012. (How) will the revolution be retweeted? Proceedings of the ACM 2012 conference on Computer Supported Cooperative Work - CSCW' 12, ACM Press, 7. http://doi.org/10.1145/2145204.2145212

43. Alex S. Taylor, Siân Lindley, Tim Regan, David Sweeney, Vasilis Vlachokyriakos, Lillie Grainger and Jessa Lingel. 2015. Data-in-Place. Proceedings of the 33 rd Annual ACM Conference on Human Factors in Computing Systems - CHI '15, ACM Press, 28632872. http://doi.org/10.1145/2702123.2702558

44. Nick Taylor, Keith Cheverst, Peter Wright, and Patrick Olivier. 2013. Leaving the wild. Proceedings of the SIGCHI Conference on Human Factors in Computing Systems - CHI '13, ACM Press, 1549. http://doi.org/10.1145/2470654.2466206
45. Nick Taylor, Justin Marshall, Alicia Blum-Ross, Justin Marshall, Alicia Blum-Ross, John Mills, Jon Rogers, Paul Egglestone, David M. Frohlich, Peter Wright and Patrick Olivier. 2012. Viewpoint. Proceedings of the 2012 ACM annual conference on Human Factors in Computing Systems - CHI '12, ACM Press, 1361. http://doi.org/10.1145/2207676.2208594

46. Aaron S. Veenstra, Narayanan Iyer, Mohammad Delwar Hossain, and Jiwoo Park. 2014. Time, place, technology: Twitter as an information source in the Wisconsin labor protests. Computers in Human Behavior 31: 65-72.

47. Vasilis Vlachokyriakos, Rob Comber, Karim Ladha, Nick Taylor, Paul Dunphy, Patrick McCorry and Patrick Olivier. 2014. PosterVote. Proceedings of the 2014 conference on Designing interactive systems DIS '14, ACM Press, 795-804. http://doi.org/10.1145/2598510.2598523

48. William Foote Whyte. 1995. Encounters with participatory action research. Qualitative Sociology 18, 3: 289-299. 